\title{
STUDIES ON THE EXPERIMENTAL GASTROINTESTINAL ULGERS PRODUCED BY RESERPINE AND STRESS
}

\section{ULCEROGENIC AGTIVITIES OF RESERPINE}

AND ITS ANALOGUES

\author{
MASAMI DOTEUCHI \\ Division of Neuropharmacology, Shionogi Research Laboratory, Shionogi \& Co., Lid., Fukushima-ku, Osaka \\ Received for publication September 11, 1967
}

The mechanism of ulcer formation by reserpine has been studied by many investigators. Recently, it was demonstrated that even a small dose of reserpine could produce considerably severe ulcers when combined with stress such as restraint (1), conflict (2), electrical stimulation of the hypothalamus $(3,4)$ and electrical shock through a grid in the floor (4).

Concerning the site of action of reserpine, Blackman et al. (5) have described that reserpine-like drugs cause gastric hemorrhage by a mechanism which has an important central component and which involves the liberation of serotonin. On the other hand, Nicoloff et al. (6) reported that norepinephrine administered into the gastric artery provoked ulceration when active acid secretion was present. From these findings it may be considered that ulcers could be produced by peripheral as well as central mechanisms. The author (7) has previously shown that a decrease in serotonin contained in the enterochromaffin cell and norepinephrine contained in vasoconstrictive nerve endings caused by reserpine and stress had close correlation with ulcer formation.

In the present paper differences in the ulcerogenic activities between reserpine and its analogues combined with electrical shock through a grid on the floor were investigated. Reserpine analogues used in this study involved two types of drugs, those that release peripheral monoamines and those that release central monoamines.

\section{METHODS}

Thirty-five cats of both sexes weighing from 2.5 to $4.0 \mathrm{~kg}$ were used. All animals were deprived of food for 16 hours previous to the experiments. Reserpine or other drugs were administered subcutaneously. Two hours after drug administration cats were placed in a cage with grids on the floor, and 5-seconds of electrical shock were given every 30 seconds for 4 hours to their body surfaces through grids (abbreviated as grid shock). The intensity of grid shock was adjusted so that shocks always elicited invariable emotional responses such as rage, fear and attempt to escape from the cage.

At the end of grid shock cats were sacrificed by decapitation under pentobarbital 
anesthesia. The stomach adjoining $15 \mathrm{~cm}$ of duodenum was removed, cut along the greater curvature and photographed. The tissue was fixed in 10\% formalin and examined histologically by means of hematoxylin-eosin staining. The severity of ulcers was determined by the grading method as follows which was modified from that developed by Kido (4).

Gastrointestinal tract was divided into three parts; i.e., corpus, pyloric area and duodenum. Lesions in each part were given the following score:

0 : no change

1: erosion

2: one to three small (less than $2 \mathrm{~mm}$ in diameter) mucosal defects

3: more than four small mucosal defects, or more than one large (greater than $2 \mathrm{~mm}$ in diameter) mucosal defect

4: small defects penetrated down to the submucosa

5: large defects penetrated down to the submucosa

6: defects penetrated down to the muscular layer

7: defects penetrated down to the serosa

8: perforated ulcer

The scores of three parts of gastrointestinal tract have been summarized and expressed as an average of the lesions. Furthermore, the incidence of cats which presented evident ulcerations (with scores ranging more than 2) were considered.

The drugs used were reserpine injection $(0.1 \%$, Dai-ichi Seiyaku), tetrabenazine injection $(0.25 \%$, Takeda Chemical Industry), syrosingopine and 10-methoxydeserpidine hydrochloride. Syrosingopine solution was prepared by dissolving $40 \mathrm{mg}$ of free base in a few drops of acetic acid and adding $0.8 \mathrm{ml}$ of propylene glycol, $0.8 \mathrm{ml}$ of ethanol and $18 \mathrm{ml}$ of distilled water. 10-Methoxydeserpidine hydrochloride was dissolved in distilled water.

\section{RESULTS}

\section{Reserpine combined with grid shock}

Two doses of reserpine, 0.1 and $1.0 \mathrm{mg} / \mathrm{kg}$, were used. Evident ulcers were produced in all animals by $0.1 \mathrm{mg} / \mathrm{kg}$ of reserpine and grid shock. Ulcers produced in three out of eight animals were so severe that they penetrated down to the submucosa (Fig. 1). The severity of ulcers produced in this experiment was almost similar to that obtained in the previous study in which grid shock was given 20 hours after the administration of 0.1 $\mathrm{mg} / \mathrm{kg}$ of reserpine (7), but the circulatory disorder found by histological examination, such as vasodilation and congestion, was more marked in the latter than in the former. When the dose of reserpine was increased to $1.0 \mathrm{mg} / \mathrm{kg}$, the severity of ulcers was also increased (Table 1). With both doses of reserpine cats were sedated and had ptosis and diarrhea. On starting the grid shock, though emotional excitement appeared instead of sedateness, ptosis and diarrhea were seen continuously. 


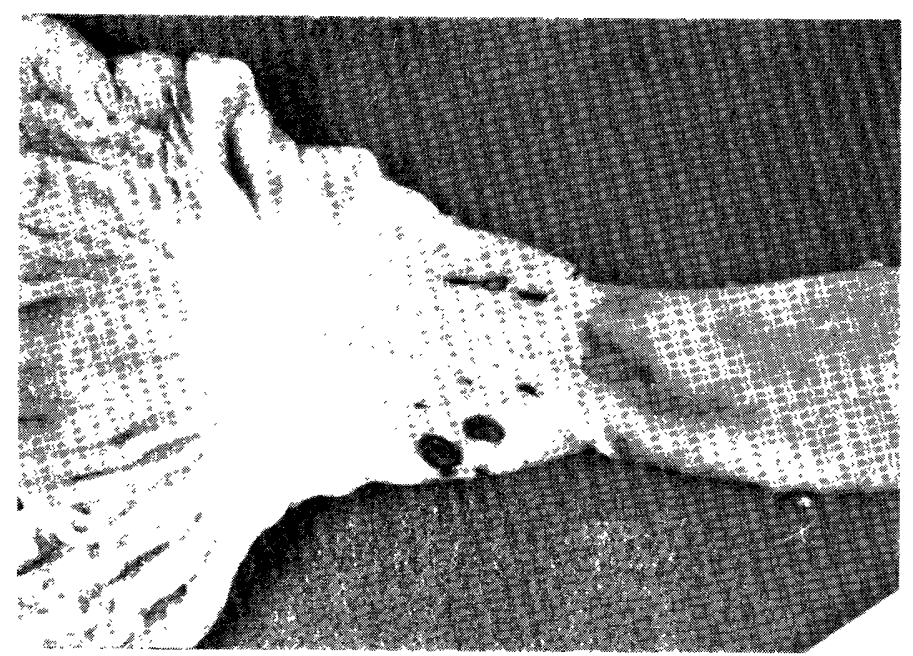

a
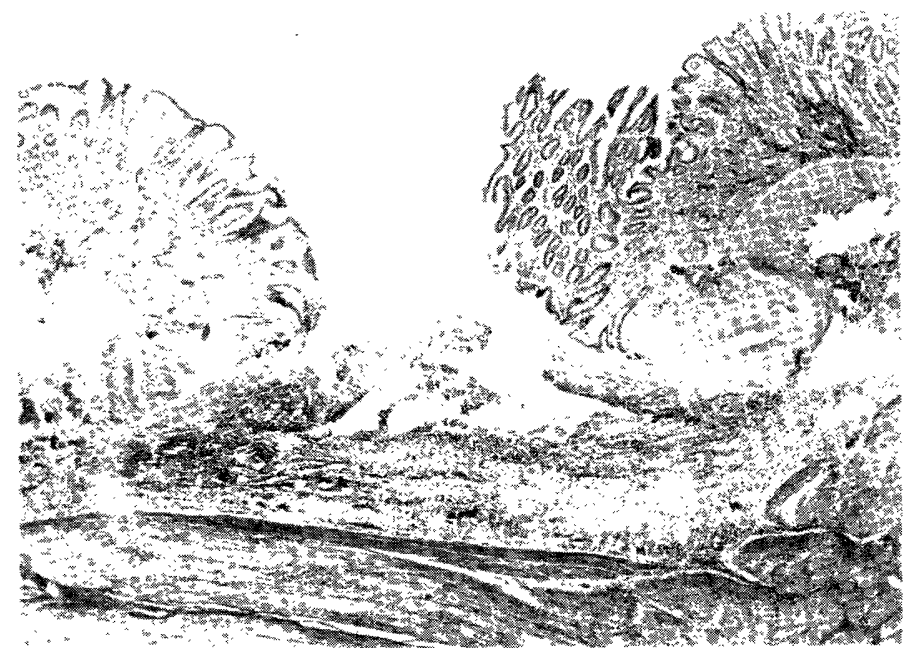

$\mathrm{b}$

FIG. 1. a. Ulcers produced by grid shock and $0.1 \mathrm{mg} / \mathrm{kg}$ of reserpine. b. Microscopic picture $(\times 32)$ of a lesion in pyloric area. Lesion has penetrated down to the submucosa.

TABLE 1. Score of lesions produced by reserpine and its analogues combined with grid shock.

\begin{tabular}{|c|c|c|c|c|c|c|c|}
\hline \multirow{2}{*}{ Drugs* } & \multirow{2}{*}{$\begin{array}{l}\text { Dose } \\
\mathrm{mg} / \mathrm{kg}\end{array}$} & \multicolumn{2}{|c|}{ No. of animals } & \multirow[b]{2}{*}{ Gorp. } & \multicolumn{2}{|c|}{ Score of lesions } & \multirow[b]{2}{*}{ Total } \\
\hline & & Used & $\begin{array}{l}\text { With } \\
\text { ulcers** }\end{array}$ & & Pylor. & Duod. & \\
\hline \multirow[t]{2}{*}{ Reserpine } & 0.1 & 8 & 8 & 0.8 & 3.7 & 1.9 & 6.4 \\
\hline & 1.0 & 4 & 4 & 1.0 & 4.0 & 3.8 & 8.8 \\
\hline \multirow[t]{2}{*}{ Syrosingopine } & 0.1 & 7 & 5 & 0.6 & 2.1 & 1.9 & 4.6 \\
\hline & 1.0 & 2 & 2 & 0 & 3.5 & 1.5 & 5.0 \\
\hline $\begin{array}{l}\text { 10-Methoxy- } \\
\text { deserpidine }\end{array}$ & 2.0 & 5 & 2 & 0 & 1.6 & 1.0 & 2.6 \\
\hline \multirow[t]{2}{*}{ Tetrabenazine } & 10 & 5 & 3 & 0.6 & 1.0 & 1.4 & 3.0 \\
\hline & 50 & 4 & 4 & 0.8 & 5.0 & 2.8 & 8.6 \\
\hline
\end{tabular}

* : Each drug was followed by 4 hours grid shock 2 hours later.

**: Erosion was not included. 
2. Syrosingopine and 10-methoxydeserpidine combined with grid shock

A small dose of syrosingopine releases peripheral monoamines without releasing central monoamines though a large dose of the drug releases either central or peripheral monoamines (8). 10-Methoxydeserpidine in doses from 2 to $4 \mathrm{mg} / \mathrm{kg}$ also lower the blood pressure continuously in cat $(9,10)$.

Ulcerogenic activities of these drugs combined with grid shock are summarized in Table 1. Syrosingopine, in a dose of $0.1 \mathrm{mg} / \mathrm{kg}$, produced evident ulcers in five out of seven animals, though the severity was less than that produced by reserpine. Most of the lesions were limited to the mucosal layer (Fig. 2). In two animals only erosions were seen in the duodenum. All animals had diarrhea, but showed neither sedateness nor ptosis.

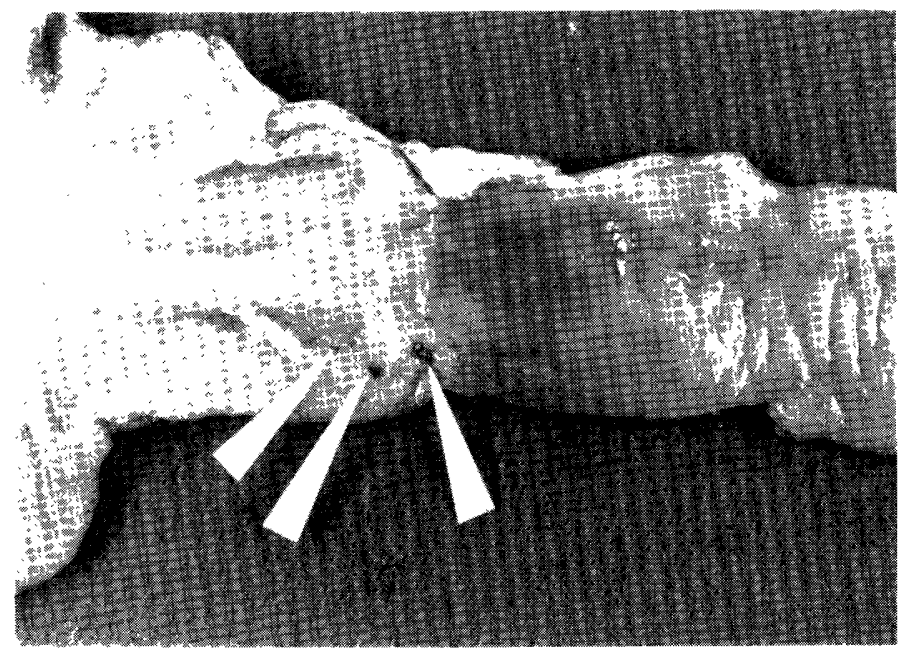

a

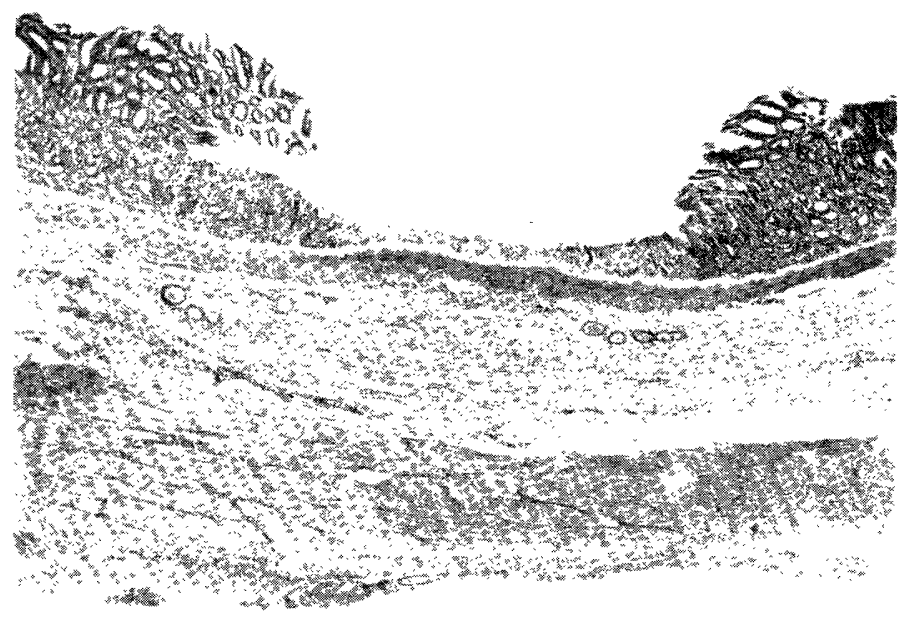

b

FIG. 2. a. Ulcers produced by grid shock and $0.1 \mathrm{mg} / \mathrm{kg}$ of syrosingopine.

b. Microscopic picture $(\times 32)$ of a lesion in pyloric area.

Lesion was limited to the mucosal layer. 


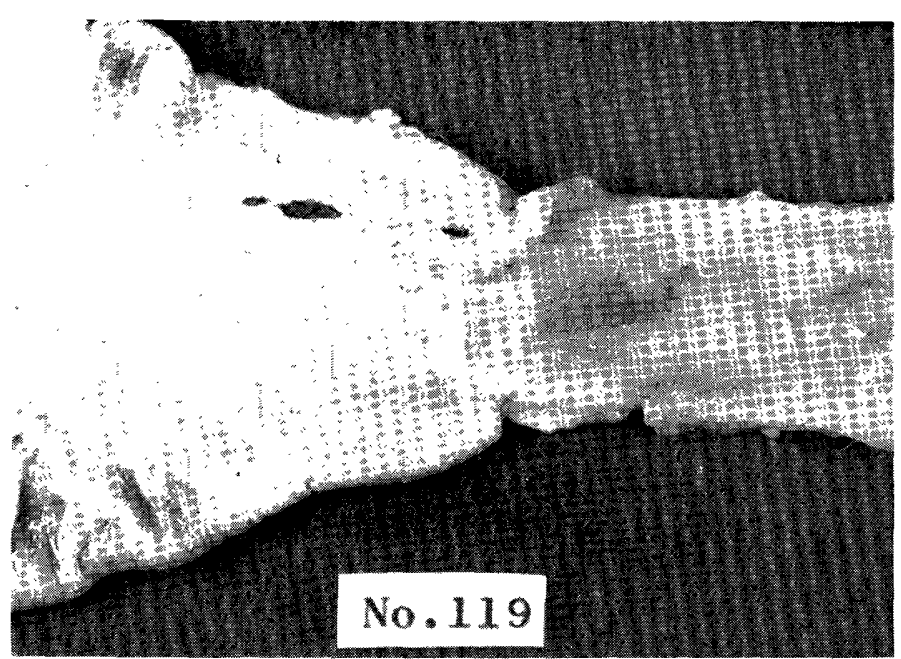

a

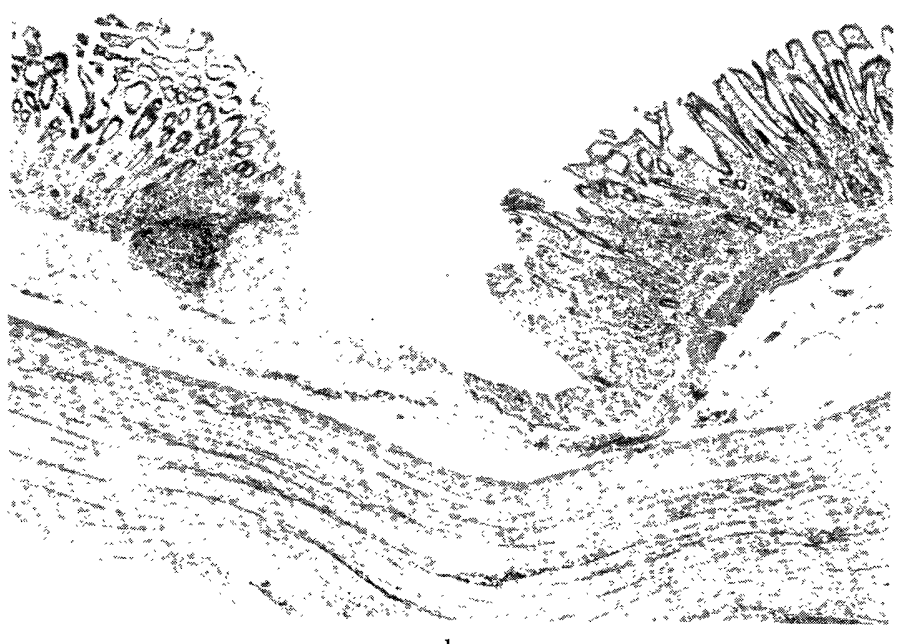

$\mathrm{b}$

Fig. 3. a. Ulcers produced by grid shock and $2 \mathrm{mg} / \mathrm{kg}$ of 10 -methoxydeserpidine.

b. Microscopic picture $(\times 32)$ of a lesion in pyloric area.

Lesion was limited to the mucosal layer.

When the dose of syrosingopine was increased to $1.0 \mathrm{mg} / \mathrm{kg}$, severity of ulcers was slightly increased and slight sedateness and ptosis were seen.

10-Methoxydeserpidine, in a dose of $2 \mathrm{mg} / \mathrm{kg}$, produced ulcers in two out of five animals and the average score of lesions in this group was less than that of syrosingopine (Fig. 3). Sedateness, ptosis and diarrhea were not observed.

\section{Tetrabenazine combined with grid shock}

Tetrabenazine has been described to release central monoamines without lowering peripheral monoamines (11). In this experiment two doses, 10 and $50 \mathrm{mg} / \mathrm{kg}$, were used. Ten $\mathrm{mg} / \mathrm{kg}$ of the drug produced evident ulcers in three out of five animals (Fig. 4) and $50 \mathrm{mg} / \mathrm{kg}$ of the drug produced severe ulcers in all animals. Fig. 5 shows a sample 


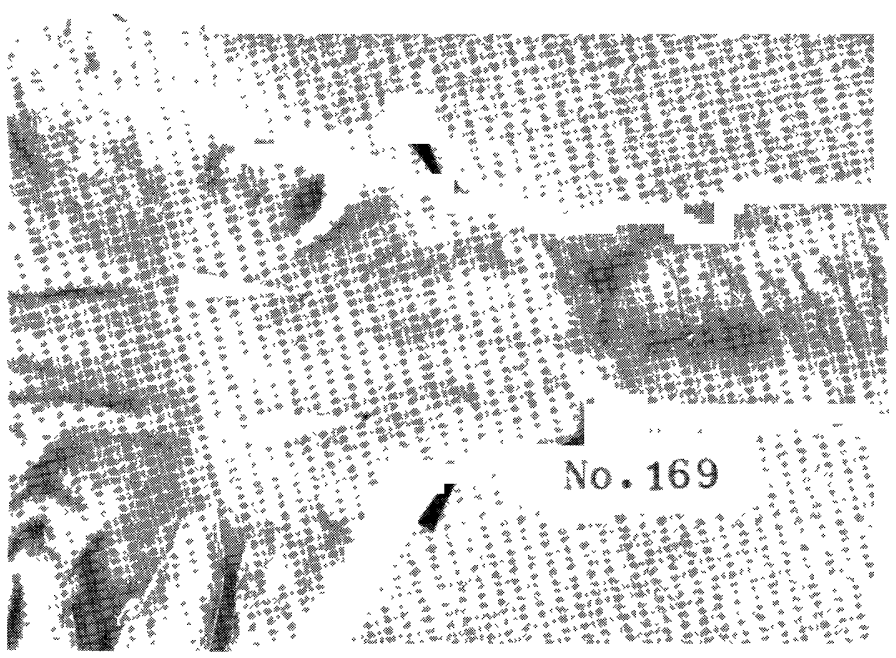

a

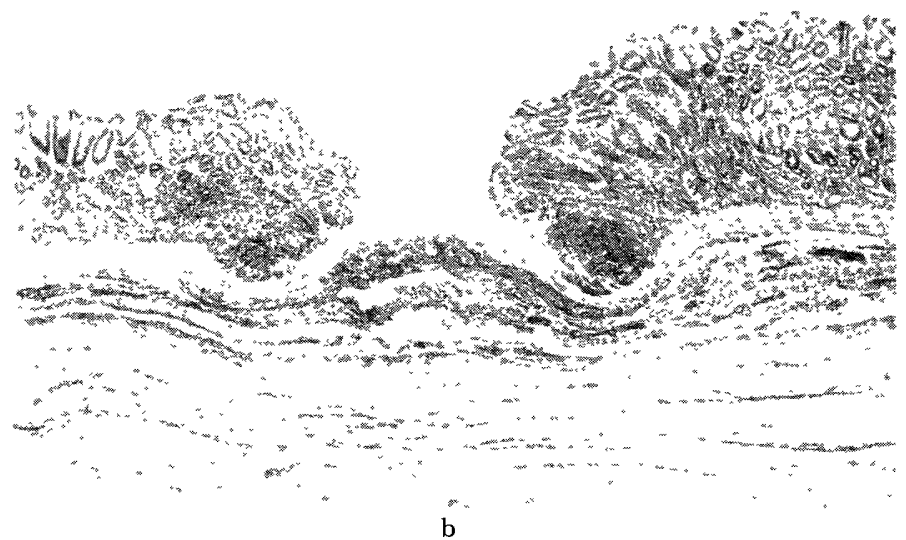

Fig. 4. a. Ulcers produced by grid shock and $10 \mathrm{mg} / \mathrm{kg}$ of tetrabenazine.

b. Microscopic picture $(\times 32)$ of a lesion in pyloric area.

Lamina muscularis mucosae was slightly lesioned.

of the severest ulcer produced by $50 \mathrm{mg} / \mathrm{kg}$ of tetrabenazine and grid shock, in which a complete perforation was seen. Sedateness and ptosis were evident with both doses but not diarrhea.

\section{DISCUSSION}

In the present paper the differences in ulcerogenic activities between reserpine and its analogues combined with grid shock were studied to predict the site of action of reserpine in producing gastrointestinal ulcers in cats. As previously reported, $0.1 \mathrm{mg} / \mathrm{kg}$ of reserpine with 4 hours of grid shock 20 hours after drug administration produced severe ulcers in the stomach and duodenum. Similar ulceration was seen in the experiment in which 


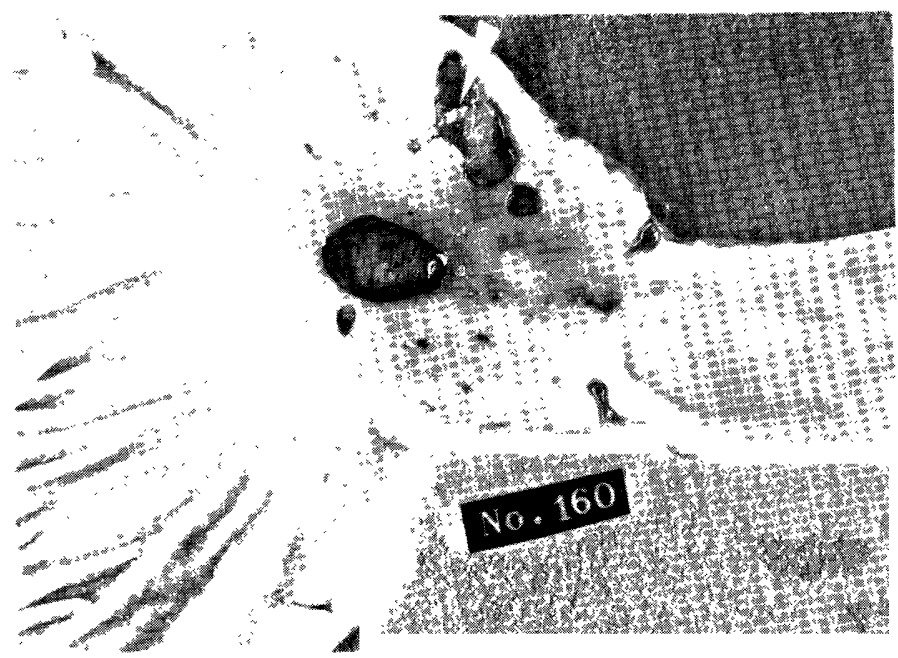

Fig. 5. Ulcers produced by grid shock and $50 \mathrm{mg} / \mathrm{kg}$ of tetrabenazine. Arrow indicates the perforated ulcer.

grid shock was given 2 hours after the administration of $0.1 \mathrm{mg} / \mathrm{kg}$ of reserpine. Some differences between the results obtained from the two different methods were found by histological examination. For example, marked congestion in either the mucosa or submucosa were seen in the former and they were seen only in the submucosa in the latter. Differences in macroscopic observation of ulcers produced by the two different methods was not found and severity of ulcers determined according to the method described above was similar to that reported previously (7). Therefore, in the present study the latter method was used as a control.

Hughes et al. (8) reported that small doses of syrosingopine release peripheral monoamines without appreciably affecting the contents of monoamines in the central nervous system. Plummer et al. (12) reported that small dose of syrosingopine caused long-lasting fall in blood pressure without sedation in dogs. 10-Methoxydeserpidine, in doses of 2 to $4 \mathrm{mg} / \mathrm{kg}$, was shown to result in continual hypotensive action in anesthetized cats $(9,10)$. Higuchi et al. (13) reported that $1 \mathrm{mg} / \mathrm{kg}$ of 10-methoxydeserpidine reduced the content of atrial norepinephrine markedly, while norepinephrine in the brain decreased slightly.

Blackman et al. (5) reported that syrosingopine has less activity in producing gastric hemorrhage and they concluded that reserpine-like drugs cause gastric hemorrhage by a mechanism which has an important central component. However, the present study showed that small doses of either syrosingopine or 10-methoxydeserpidine which failed to cause central depression could produce ulcers when combined with grid shock. Since almost no change was caused in the gastrointestinal tract by grid shock alone (7), it is undoubted that decrease in peripheral monoamines by these drugs accelerates the formation of ulcers. As Kido (4) has described, grid shock, as a mode of stimulation of the peripheral nerve, may be considered as a source of stimulant physiologically by exciting the hypothalamus because emotional responses to hypothalamic stimulation closely resembled those elicited by grid shock. Thus, it may be considered that stimula- 
tion of the central nervous system, especially the hypothalamus, in animals in which peripheral monoamines were decreased led to ulceration, though the frequency of incidence and severity of ulcers were less than that produced by reserpine combined with grid shock, which could release both central and peripheral monoamines.

On the other hand, tetrabenazine was shown to release brain monoamines and produce central action typical of reserpine without lowering the peripheral amines $(11,14)$. According to the observation of Quinn et al. (11) and Shore et al. (15), it may be considered that the dose of tetrabenazine comparable to $0.1 \mathrm{mg} / \mathrm{kg}$ of reserpine in releasing central monoamines may be smaller than $10 \mathrm{mg} / \mathrm{kg}$. In the present study severe ulcers were produced by $50 \mathrm{mg} / \mathrm{kg}$ of tetrabenazine which could be compared with those produced by $1.0 \mathrm{mg} / \mathrm{kg}$ of reserpine, but only slight graded ulcers were produced by 10 $\mathrm{mg} / \mathrm{kg}$ of tetrabenazine which were markedly less than those produced by $0.1 \mathrm{mg} / \mathrm{kg}$ of reserpine. These findings may suggest that decrease in central monoamines without change in peripheral monoamines is not sufficient to produce severe ulcers which could be compared with those produced by reserpine. That syrosingopine and 10-methoxydeserpidine could produce ulcers may support this suggestion and also shows the possibility of the decrease in peripheral monoamines as well as in central monoamines as contributing a role in production of ulcers in the gastrointestinal tract of cats.

\section{SUMMARY}

Differences in ulcerogenic activities between reserpine, syrosingopine, 10-methoxydeserpidine and tetrabenazine combined with grid shock were studied. The most potent activity was found with reserpine. Syrosingopine and 10-methoxydeserpidine, in doses causing diarrhea but not sedateness and ptosis, produced evident ulcers in more than $60 \%$ of the animals when they were given four hours of grid shock 2 hours after drug administration. Tetrabenazine, which caused sedateness and ptosis but not diarrhea, also produced evident ulcers when given similar grid shock. These findings suggest the possibility that decrease in peripheral as well as central monoamines is involved even partially in ulcer formation by reserpine and stress.

Acknowledgment: The author thanks Dr. R. Kido for many helpful discussions and suggestions. Thanks are also given to Dr. T. Otsuji and Mr. H. Tanaka for their skillful technical assistance.

\section{REFERENCES}

1) Hartry, A.L.: J. comp. physiol. Psychol. 55, 719 (1962)

2) Sawrey, J.M. and Sawrey, W.L.: Ibid. 57, 307 (1964)

3) Nishizaki, H., Yамamoto, K. and Kido, R.: Folia pharmac. jap. 60, 1468 (1964)

4) Krdo, R.: Brain and Nerve 19, 467 (1967)

5) Blackman, J.G., Campion, D.S. and Fastier, F.n.: Br. J. Pharmac. Chemother. 14, 112 (1959)

6) Nicoloff, D.M., Peter, E.T., Leonard, A.S. and Wangensteen, O.H.: J. Am. med. Ass. 191, 383 (1965)

7) Doteuchi, M.: This Journal 17, 638 (1967) 
8) Hughes, F.B., Finger, K.F. and Brodie, B.B.: J. Pharmac. exp. Ther. 128, 131 (1960)

9) Mrr, B.J. and Lewiss, J.J.: J. Pharm. Pharmac. 12, 677 (1960)

10) Peterfalvi, M. and Jequier, R.: Archs int. Pharmacodyn. Thér. 124, 237 (1960)

11) Quinn, G.P., Shore, P.A. And Brodie, B.B.: J. Pharmac. exp. Ther. 127, 103 (1959)

12) Plummer, A.J., Barrett, W.E., Maxwell, R.A., Finocchio, D., Lucas, R.A. and Earl, A.E.: Archs int. Pharmacodyn. Thér. 119, 245 (1959)

13) Higuchi, H., Matsuo, T., Nakatani, G. and Shimamoto, K.: This Journal 13, 36 (1963)

14) Pletscher, A., Bessendorf, H. and Bachtold, H.P.: Arch. exp. Path. Pharmak. 232, 499 (1958)

15) Shore, P.A., Pletscher, A., Tomich, E.G., Carlsson, S., Kuntzman, R. and Brodie, B.B.: Ann. N.Y. Acad. Sci. 66, 609 (1957) 